\title{
La enésima reforma de la Disposición Adicional Décima del Estatuto de los Trabajadores
}

\author{
The $\mathrm{N}^{\text {th }}$ amendment of the Tenth Additional Provision \\ of the Workers' Statute
}

\author{
Amparo Esteve Segarra \\ Profesora titular de Derecho del Trabajo y la Seguridad Social. Acreditada CU \\ Universidad de Valencia
}

ORCID ID: 0000-0003-3773-4668

doi: https://doi.org/10.20318/labos.2022.6646

Lesumen: Lasposición adicional décima del ET ha sufrido cambios constantes en suce-
sivas reformas. La última versión del precepto pretende prohibir las jubilaciones
forzosas previstas en los convenios colectivos por debajo de los 68 años y esta-
blece como única justificación de política de empleo la nueva contratación de
un trabajador con un contrato indeterminado y a jornada completa. Además,
se introduce una medida de acción positiva para fomentar la contratación de
nuevas trabajadoras que cubran los puestos de trabajo de los jubilados forzo-
samente en sectores de baja ocupación femenina, posibilitando la rebaja de la
edad de jubilación en las cláusulas convencionales de jubilación forzosa hasta la
edad ordinaria de jubilación.

Palabras clave: jubilación forzosa, convenio colectivo, política de empleo, jubilación activa

Abstract: The tenth additional provision of the ET has undergone constant changes in successive reforms. The latest version of the precept aims to prohibit forced retirements provided for in collective agreements below 68 years of age and establishes as the only justification for the employment policy the new hiring of a worker with an indeterminate contract and full time. In addition, a positive action measure is introduced to encourage the hiring of new workers to fill the jobs of forced retirees in sectors with low female employment, making it possible to lower the retirement age in the conventional clauses of forced retirement up to normal retirement age.

Keywords: $\quad$ Forced retirement, collective agreement, employment policy, active retirement. 


\section{La orientación de la reforma del 2021: prohibir las cláusulas de jubilación forzosa por de- bajo de los 68 años}

Pocas instituciones en el Estatuto de los Trabajadores han estado sometidos a tan notables vaivenes normativos como la posibilidad de pactar convencionalmente la finalización del contrato de trabajo por jubilación por razones de política de empleo. La Disposición adicional décima del Estatuto de los Trabajadores ha sido históricamente la que contenía la habilitación legal para que los convenios colectivos pudieran establecer cláusulas de jubilación forzosa ${ }^{1}$. La mencionada habilitación, muerta y resucitada no en una, sino en varias ocasiones, habría sido objeto de numerosas reformas legales ${ }^{2}$, y la del 2021 también ha modificado su redacción ${ }^{3}$.

La ley 20/2021, de 28 de diciembre, ubica la modificación de la DA 10ª ET en las políticas de jubilación activa. Este objetivo se hace patente a partir de dos elementos:

1. La propia redacción literal de la DA 10a ET que comienza señalando: "En aras de favorecer la prolongación de la vida laboral...”. Y a continuación, fija indirectamente una prohibición de cláusulas convencionales que prevean la jubilación forzosa del trabajador a una edad inferior a los sesenta y ocho ańos. La prohibición es indirecta porque se admite sólo la operatividad de las cláusulas de los convenios colectivos cuando los trabajadores tengan 68 años o más.

${ }^{1}$ La primera previsión de la jubilación forzosa en el ordenamiento laboral fue la contenida en la disposición adicional quinta del Estatuto de los Trabajadores de 1980 (Ley 8/1980, de 10 de marzo). Esta disposición no introducía una figura desconocida, pues las jubilaciones forzosas se hallaban previstas en el ordenamiento funcionarial, ni en el ordenamiento laboral, donde ya existían jubilaciones forzosas, si bien, con carácter atípico. Así, la Orden Ministerial de 1 de julio de 1953 (BOE de 7 de julio, núm. 188) consagró la jubilación como un derecho del trabajador, dejando a salvo la posibilidad del empresario de extinguir el contrato de trabajo por ineptitud. Sin embargo, el bajo rango normativo en el que se estableció la voluntariedad de la jubilación permitió que posteriores órdenes ministeriales regularan jubilaciones forzosas. Así la Dirección General de Trabajo mediante una resolución de 1 de mayo de 1954 estableció la subsistencia del régimen de jubilación establecido para el Banco de España por Orden de 21 de diciembre de 1948. En segundo lugar, la Orden del Ministerio de Trabajo de 18 de enero de 1955 exceptuó la aplicación de la Orden de 1 de julio de 1953 en diversas reglamentaciones.

${ }^{2}$ En la DA 50 del ET de 1980 se establecía una edad máxima de 69 años, lo que planteó inmediatamente problemas de interpretación y dudas acerca de la constitucionalidad de la regulación prevista. La institución, que rompería la que hasta ese momento era configuración típica de la jubilación como causa de extinción de la relación laboral como derecho, recibiría el aval del Tribunal Constitucional, con fundamento en un reparto del empleo. Sin embargo, la edad máxima de trabajo fue eliminada posteriormente. De este modo la regulación se sustituyó por la disposición adicional décima del ET, admitiendo la jubilación forzosa como instrumento de política de empleo. La disposición fue nuevamente objeto de reforma en el Real Decreto-Ley 5/2001, de 2 de marzo, de Medidas Urgentes de Reforma del Mercado de Trabajo (BOE núm. 64, 3-3-2001) convalidado después por la posterior Ley 12/2001, de 9 de julio, Medidas Urgentes de Reforma del Mercado de Trabajo para el incremento del empleo y la mejora de su calidad (BOE núm. 164, 10-7-2001) que procederían a la derogación de la mencionada disposición. Un giro completo se produjo con la Ley 14/2005, de 1 de julio, que habría facilitado de nuevo la posibilidad de jubilaciones forzosas convencionales. Este giro respondía a la reivindicación de los agentes sociales de recuperar la institución, así como al momento de fortaleza de las arcas públicas. El nuevo capítulo de la historia normativa se ubicaría en la gran reforma de la pensión de jubilación operada por la Ley 27/2011. Pese a la recomendación 12a de la Comisión del Pacto de Toledo contenida en el informe del 2011 de eliminar la jubilación obligatoria e incentivar el retraso de la jubilación de forma voluntaria, la Ley 27/2011, en su DA 36a mantuvo la posibilidad de cláusulas convencionales de jubilación forzosa en la DA 10 a del ET, con dos ajustes: que la jubilación forzosa exigiría el cumplimiento de la edad ordinaria de jubilación en cada momento y la exigencia de que el trabajador afectado pudiera alcanzar el 80 por cien de la base reguladora de su pensión de jubilación. Empero, la Ley 27/2011 no tendría efectos, puesto que poco tiempo después de la aprobación de la ley y antes incluso de su entrada en vigor (el 1 de enero de 2013 conforme a la disposición final duodécima de la Ley 27/2011), se volvería a modificar el texto de la disposición adicional décima del ET. A la postre, la posibilidad de incluir en los convenios colectivos cláusulas de jubilación forzosa se derogaría en la Ley 3/2012, de 6 de julio, de medidas urgentes para la reforma del mercado laboral (BOE núm. 182, 7-7-2012) en concreto en la DF 4a a apartado 2. Posteriormente, el art. 1 del RD-L 28/2018, de 28 de diciembre, volvería a reintroducir la posibilidad de jubilaciones forzosas establecidas en convenio colectivo.

${ }^{3}$ Vid. DA $1^{\text {a }}$ Ley 21/2021, de 28 de diciembre, de garantía del poder adquisitivo de las pensiones y de otras medidas de refuerzo de la sostenibilidad financiera y social del sistema público de pensiones. 
2. El segundo elemento que evidencia la orientación es el propio preámbulo de la norma que, al prologar la reforma introducida, la sitúa entre las medidas para posibilitar una jubilación activa ${ }^{4}$, en línea con las mayores penalizaciones para las jubilaciones anticipadas y la promoción del envejecimiento activo a través de la llamada jubilación demorada.

La reforma se enmarca en un contexto pandémico y delicado por la situación financiera de déficit, la utilización sucesiva del fondo de reserva y los desafíos demográficos del sistema de Seguridad Social, que impondría retos al sistema de protección social, en particular, en materia de pensiones de la jubilación. Las razones del cambio serían tanto económicas como políticas. Entre las primeras se aludiría a la necesidad de promover el envejecimiento activo, término eufemístico para aludir a la necesidad de prolongar la vida laboral, por el incremento en gasto en pensiones, la minoración en las cotizaciones sociales y las presiones demográficas. Sin embargo, también existiría una concreta orientación política en la reforma laboral del 2021. Y es que las antedichas razones ligadas a la viabilidad del sistema, ya se habrían invocado con anterioridad en la década pasada para modificar la DA $10^{a}$ ET, derogando la posibilidad de jubilaciones forzosas por la vía del convenio colectivo. Pero, a diferencia de reformas anteriores instadas por gobiernos de orientación conservadora ${ }^{5}$, se optaría por mantener la posibilidad de una extinción por razón de la edad en los convenios colectivos, pero sujetándola a requisitos más estrictos de política de empleo y de edad de los trabajadores jubilados.

\section{Los cambios más relevantes de la reforma del 2021}

\subsection{La prohibición de las jubilaciones forzosas por debajo de los 68 años}

Se prohíben las cláusulas convencionales de jubilación forzosa por debajo de los 68 años. La fijación de un límite mínimo para habilitar cláusulas convencionales supone un planteamiento distinto a versiones anteriores, porque no se trata de derogar la habilitación legal a las cláusulas convencionales de jubilación forzosa, sino de limitarlas por la vía de incrementar la edad mínima en la que pueden producirse. La fijación de un suelo de 68 años se sitúa en la tendencia al alargamiento de la edad legal de jubilación pensionable en nuestro ordenamiento, situada desde 1919 (R.D. de 11 de marzo de 1919, Gaceta del 12) en los 65 ańos, y que se ha ido alargado progresivamente, por mor de la Ley 27/2011. La edad de 68 ańos fijada como mínima para la legalidad de las cláusulas de jubilación forzosa es, curiosamente, próxima a la que en otro momento fue la edad máxima de trabajo, que en el ET de 1980 se situaba en los 69 años.

\footnotetext{
${ }^{4}$ Así se señala: "Por lo que a la jubilación activa se refiere, en coherencia con todo lo anterior, se exige como condición para acceder a esta modalidad de jubilación el transcurso de al menos un año desde el cumplimiento de la edad ordinaria de jubilación. Por último, se contempla la prohibición de cláusulas convencionales que prevean la jubilación forzosa del trabajador a una edad inferior a los sesenta y ocho años, así como la reducción del 75 por ciento de las cuotas empresariales a la Seguridad Social por contingencias comunes durante la situación de incapacidad temporal de los trabajadores que hayan cumplido sesenta y dos años de edad".

${ }^{5}$ El Real Decreto-Ley 5/2001, de 2 de marzo, de Medidas Urgentes de Reforma del Mercado de Trabajo (BOE núm. 64, 3-32001) convalidado después por la posterior Ley 12/2001, de 9 de julio, Medidas Urgentes de Reforma del Mercado de Trabajo para el incremento del empleo y la mejora de su calidad (BOE núm. 164, 10-7-2001) que procederían a la derogación de la mencionada disposición por necesidades demográficas ligadas al equilibrio del sistema de protección social y la necesidad de incentivar la prolongación de la vida activa. El legislador exponía en el RDL 5/2001, que la jubilación forzosa configurada originalmente como estímulo o instrumento de política de empleo, estaba inspirada en "concepciones y apoyada en realidades demográficas y del mercado de trabajo claramente desactualizadas". En este sentido, las líneas del Pacto de Toledo desde una perspectiva de preocupación por la financiación del sistema de Seguridad Social desincentivaban las jubilaciones anticipadas y, en la misma línea desde instancias comunitarias, se promovía una jubilación voluntaria y progresiva.
} 
El fijar una edad elevada para permitir la jubilación forzosa prevista en el convenio colectivo parece dar por superadas las tendencias sostenidas en otras etapas históricas de reducir la edad de acceso a la pensión de jubilación y, en general, promover las jubilaciones, como medida de política de empleo, dado que diversos estudios incidirían en la escasa eficacia de estas medidas de potenciar la salida de determinados colectivos de trabajadores y la entrada de otros, para contribuir a reducir la tasa de desempleo y aliviar el problema de desempleo juvenil. Ello explica los giros del legislador en cuanto a la posibilidad de establecer en convenios colectivos cláusulas de jubilación forzosa.

\subsection{La redefinición de la politica de empleo en términos más estrictos para conseguir el relevo generacional}

La nueva cláusula define en términos mucho más concretos que en su versión anterior, los objetivos de política de empleo. Y ello, no sólo porque se cambia la redacción en el sentido de suprimir la enumeración de los objetivos de política de empleo con carácter meramente enunciativo que se contenía en la versión anterior ${ }^{6}$; sino porque se utiliza en la nueva redacción un término concreto y claramente vinculante, de manera que sólo cabe la admisión de la jubilación forzosa si se produce un solo objetivo, la contratación de un nuevo trabajador o trabajadora por tiempo indefinido y a jornada completa. Así se señala como requisito que la medida de jubilación forzosa "deberá vincularse, como objetivo coherente de politica de empleo expresado en el convenio colectivo, al relevo generacional a través de la contratación indefinida y a tiempo completo de, al menos, un nuevo trabajador o trabajadora". La redacción de la norma despeja parte de los problemas relacionados con el cese en el trabajo por razón de la edad vinculados a objetivos de política de empleo, que se delimitan de una forma mucho más estricta. Ello va a obligar a un cambio de redacción de muchas cláusulas convencionales en los convenios que se suscriban a partir del 2022, en contraposición con las cláusulas convencionales que, hasta esa fecha venían contemplando un elenco de medidas de políticas de empleo mediante la transformación de contratos a tiempo parcial en a tiempo completo, de contratos temporales en indefinidos, suscripción de contratos de relevo o nuevas contrataciones por cada extinción (sobre el régimen de vigencia de estas cláusulas vid. infra el apartado dedicado al derecho transitorio). Ahora sólo se admite esta última posibilidad y con un contrato indefinido y a jornada completa.

La razón de ser de este cambio es tratar de evitar la amortización de puestos de trabajo por la vía de la jubilación forzosa. El objetivo no es novedoso, pues el TC en una de sus primeras resoluciones, en concreto, en la sentencia de 2 de julio de 1981, ya había dicho que la jubilación era voluntaria en el ámbito privado como regla general y que las jubilaciones forzosas se justificaban sólo por objetivos de reparto de empleo. El problema es que en la práctica ello se fue relativizando, de manera que las finalidades de política de empleo se presumían y parecía que bastaba que el jubilado tuviera derecho a la pensión y luego ya se vería si su puesto se cubría, con quién o si este se amortizaba.

El Tribunal Constitucional en sentencia de 2 de julio de 1981, establecería que la institución de la jubilación forzosa tendría como fundamento una política de reparto de empleo, la cual plasma una determinada concepción del valor general de solidaridad. Es justamente, este valor de solidaridad -que se concreta en el aspecto colectivo del derecho al trabajo- el que justifica la anulación del derecho del trabajador a decidir su jubilación, limitando el aspecto individual de ese mismo derecho. La doctrina de la sentencia sirvió de pauta interpretativa para los posteriores pronunciamientos del Tribunal Constitucional en materia de jubilación forzosa vía negociación colectiva. Esta justifi-

\footnotetext{
${ }^{6}$ Estos objetivos se enunciaban anteriormente de la manera siguiente: "tales como la mejora de la estabilidad en el empleo por la transformación de contratos temporales en indefinidos, la contratación de nuevos trabajadores, el relevo generacional o cualesquiera otras dirigidas a favorecer la calidad del empleo".
} 
cación inicialmente parecía ligada al requisito de no amortización de puestos de trabajo. Pero este condicionamiento luego no se seguiría en la jurisprudencia constitucional, que ya no hizo mención de este requisito en las sentencias de 1985, ni en la jurisprudencia de finales de los ochenta y de los noventa, que formó un concepto de política de empleo indeterminado. Así se estableció que para la validez de las jubilaciones forzosas basta que se garanticen los derechos a la pensión del trabajador jubilado, pues las finalidades de política de empleo se presumen, STS de 2 de junio de 1986. El TS también admitió que con las jubilaciones forzosas pudieran producirse una reducción de plantilla, precisamente por razones de política de empleo para amortizar puestos de trabajo y superar una situación crítica de la empresa (STS de 2 de marzo de 1983, FJ. 3º). Ello se trasladaría a la doctrina judicial que admitió establecer medidas de jubilación forzosa para garantizar la viabilidad de la empresa o para evitar despidos colectivos (STSJ de Galicia de 29 de octubre de 1996). En esencia, la limitación del derecho individual del trabajador jubilado se fundamentaba en un concepto de política de empleo, pero el concepto estaba aquejado de un cierto grado de indeterminación, lo que permitiría una relativización.

La reforma del 2021 trataría de volver al inicio, permitiendo sólo las jubilaciones forzosas cuando no se amortizara el puesto de trabajo del trabajador jubilado, y, además, el trabajador contratado para cubrir su puesto lo fuera en las condiciones de un empleo típico (indefinido y a jornada completa). A la concreta exigencia, ha contribuido la experiencia pasada de cuatro décadas. Y es que la configuración de la jubilación forzosa como potencial instrumento de reparto de empleo ha adolecido siempre controles que garantizasen el cumplimiento del fin que le servía de fundamento. Es preciso tener en cuenta que la introducción de la disposición adicional quinta del ET de 1980 creó importantes expectativas en cuanto a los efectos automáticos de la medida como instrumento de creación o, más bien, de reparto de empleo. Sin embargo, su uso pronto generaría una actitud más escéptica en la doctrina científica, cuando no claramente negativa al comprobar la utilización no como instrumento de creación de empleo, sino como una medida para amortizar puestos de trabajo y facilitar la salida de las empresas de situaciones de crisis. Téngase en cuenta que la jubilación forzosa frente a otras soluciones como los despidos colectivos ofrece importantes ventajas de simplicidad de trámites y de costes, ya que sólo existe como indemnización, la pensión de jubilación, frente a otras indemnizaciones más elevadas (art. 53 TRET). Es verdad que, en el ámbito de la jubilación forzosa pueden y suelen preverse mejoras voluntarias, tales como premios de jubilación, pero si no existe previsión al respecto, no existe obligación.

Los tribunales posteriormente intentaron acotar mejor la explicitación de estos objetivos en los convenios, pero ello no se consiguió nunca del todo ${ }^{7}$. A estos efectos, la jurisprudencia ha establecido que no sólo es necesario que el convenio exprese formalmente los objetivos de política de empleo, sino que es obligatorio que se pruebe que dichos objetivos se han cumplido o están en trámite de cumplimiento $^{8}$. Si se han cumplido, los tribunales legitiman las jubilaciones forzosas, aunque las mismas causen un perjuicio a los trabajadores que se jubilan, que no pueden acceder a incrementos en la pensión de jubilación por prolongar su vida activa o pierden poder adquisitivo por las diferencias entre su pensión y la retribución que tenían en activo. En conclusión, aunque los tribunales han establecido una doctrina en la que se intentaba ser más exigente con las finalidades de política de empleo fijadas en el convenio, pero esta doctrina ha tenido escaso impacto por dos factores:

7 Vid. Alfonso Mellado et altri: Capítulo sobre "Contratación, Fomento del Empleo y Extinción” del Observatorio de Negociación colectiva Fundación Primero de Mayo, 2022, (en prensa). En el análisis se concluye que muchos de los convenios se limitaban a enunciar con carácter ejemplificativo las medidas posibles de política de empleo establecidas en la versión anterior de la DA10 ${ }^{\mathrm{a}} \mathrm{ET}$.

${ }^{8}$ STS 4 mayo 2017 y, aplicando la citada doctrina, a la acreditación efectiva del cumplimiento de las medidas, STSJ Galicia 28 enero 2021, rec. 3289/2020. 
- La escasa litigiosidad de las cláusulas de jubilación forzosa de los convenios colectivos en el sector privado. Ha habido conflictividad, pero ésta se ha concentrado mayormente en el ámbito del empleo público, en concreto en el personal estatutario y por otros motivos (derecho a prolongar la actividad hasta los 70 en particular del personal estatutario) ${ }^{9}$.

- Cierta inercia en la redacción de los convenios colectivos, en los que en muchos casos se mantenían redacciones de cláusulas de convenios anteriores, al margen de los cambios de redacción de la DA $10^{\text {a }}$ ET.

\subsection{La orientación de género}

2.3.1. Los menos importantes: los cambios formales de supresión del masculino genérico

La reforma ha profundizado en la línea de los cambios formales de redacción relativos a la sustitución de "trabajador" por términos neutros como "persona trabajadora" o "persona afectada" o "trabajador o trabajadora". Este uso de un lenguaje androcéntrico o no sexista es una orientación de la LOIEMH y de diversos organismos internacionales que lo fijan como recomendación ${ }^{10}$. Sin embargo, el uso del género gramatical masculino como universal en una lengua como el castellano que tiene un lenguaje de sustantivos por géneros, es una cuestión polémica, que para algunos supone una discriminación y subordinación lingüística, fruto de una visión androcéntrica del mundo y de la lengua; mientras que para otros es simplemente una regla gramatical, sin connotaciones sexistas.

2.3.2. La rebaja de la edad de jubilación forzosa por razón de género y la medida de acción positiva de contratar mujeres en determinados sectores con tasas de ocupación femenina inferior al 20\%

Una de las novedades más importantes de la reforma es que se establece un sesgo de género en los requisitos de la jubilación forzosa para alcanzar la igualdad entre sexos introduciendo una medida de acción positiva, que como es sabido, tiene amparo en el art. 11 de la LOI 3/2007. Comienza el precepto señalando que este sesgo se configura como excepción. Así se dice literalmente: "Excepcionalmente, con el objetivo de alcanzar la igualdad real y efectiva entre mujeres y hombres coadyuvando a superar la segregación ocupacional por género, el límite del apartado anterior podrá rebajarse hasta la edad ordinaria de jubilación fijada por la normativa de Seguridad Social cuando la tasa de ocupación de las mujeres trabajadoras por cuenta ajena afiliadas a la Seguridad Social en alguna de las actividades económicas correspondientes al ámbito funcional del convenio sea inferior al 20 por ciento de las personas ocupadas en las mismas".

\footnotetext{
${ }^{9}$ Un estudio de estos conflictos en RODRÍGUEZ CARDO, I.A. (2016). La jubilación forzosa de los funcionarios públicos (y en especial del personal estatutario). Trabajo y Derecho (14). pp. 1-7.

${ }^{10}$ Vid. Resolución 109 aprobada por la Conferencia General de la UNESCO, en su 25a reunión, párrafo 3, 1989. Tras ellas, elaboró la publicación "Recomendaciones sobre un uso no sexista del lenguaje" de 1991, que inicia señalando "El lenguaje no es una creación arbitraria de la mente humana, sino un producto social e histórico que influye en nuestra percepción de la realidad. Al transmitir socialmente al ser humano las experiencias acumuladas de generaciones anteriores, el lenguaje condiciona nuestro pensamiento y determina nuestra visión del mundo". Y también, la Recomendación de 21 de febrero de 1990 aprobada por el Comité de Ministros del Consejo de Europa, núm. R (90), constituye la primera regulación sobre la eliminación del sexismo en el lenguaje, en la que subrayan "elpapel fundamental que tiene el lenguaje en la formación de la identidad social de los individuos y la interacción que hay entre el lenguaje y las actitudes sociales", y expresan que "el sexismo que se refleja en el lenguaje utilizado en la mayor parte de los estados miembros del Consejo de Europa — que hace predominar lo masculino sobre lo femenino - constituye un estorbo al proceso de instauración de la igualdad entre mujeres y hombres, porque oculta la existencia de las mujeres, que son la mitad de la humanidad, y niega la igualdad entre hombre y mujer".
} 
Se trata de posibilitar la rebaja de la edad de jubilación forzosa en los convenios del mínimo de 68 años a la edad ordinaria de jubilación fijada en la normativa de Seguridad Social. Para ello, se han de cumplir una serie de requisitos.

El primero es que la tasa de ocupación de las mujeres trabajadoras por cuenta ajena en la actividad económica correspondiente al ámbito funcional del convenio sea inferior al 20 por ciento, en los términos de cálculo que fija la propia DA $10^{\mathrm{a}} \mathrm{ET}^{11}$.

El segundo requisito reitera la condición de que la jubilación forzosa sólo puede operar cuando el trabajador o trabajadora jubilado tenga derecho al 100 por 100 de la pensión de jubilación en su modalidad contributiva.

El tercer requisito es que cada extinción contractual en aplicación de esta previsión deberá llevar aparejada simultáneamente la contratación indefinida y a tiempo completo de, al menos, una mujer en la mencionada actividad.

Finalmente, se establece la previsión de que la decisión extintiva de la relación laboral será comunicada por la empresa a los representantes legales de los trabajadores y a la propia persona trabajadora afectada, con carácter previo, pero sin fijar un concreto plazo. Obviamente esta medida informativa se encamina, sobre todo, en el caso de los representantes, a un control del cumplimiento de los requisitos anteriores.

\section{El régimen de transitoriedad}

La DA $10^{\text {a }}$ del ET tiene un régimen temporal que trata de evitar la enorme litigiosidad que generaron otras reformas anteriores del precepto, como la derogación de la posibilidad de jubilaciones forzosas producida en 2001. La DT 9a de la Ley 21/2021, de 28 de diciembre, de garantía del poder adquisitivo de las pensiones y de otras medidas de refuerzo de la sostenibilidad financiera y social del sistema público de pensiones, contiene dos reglas: En primer lugar, la nueva redacción de las cláusulas de jubilación forzosa, sólo se aplica a los convenios colectivos que se suscriban a partir del 1 de enero del 2022. En segundo lugar, respecto de los convenios colectivos suscritos con anterioridad a esta fecha, las cláusulas de jubilación forzosa podrán ser aplicadas hasta tres años después de la finalización de la vigencia inicial pactada del convenio en cuestión. Las anteriores cláusulas de jubilación forzosa de convenios previos van a mantener durante la vigencia del convenio y más allá porque se prevé que se aplicarán hasta 3 años después de finalización de la vigencia del convenio.

\section{El contraste con la vigencia de la jubilación forzosa en el ámbito funcionarial}

La jubilación forzosa ha tenido su origen en el ámbito funcionarial, donde ha pervivido con un régimen diferente y regulado por la ley. El establecimiento de una edad diferente plantea cuestiones

\footnotetext{
${ }^{11}$ Se establece que "Las actividades económicas que se tomarán como referencia para determinar el cumplimiento de esta condición estará definida por los códigos de la Clasificación Nacional de Actividades Económicas (CNAE) en vigor en cada momento, incluidos en el ámbito del convenio aplicable según los datos facilitados al realizar su inscripción en el Registro y depósito de convenios y acuerdos colectivos de trabajo y planes de igualdad (REGCON), de conformidad con el artículo 6.2 y el anexo 1 del Real Decreto 713/2010, de 28 de mayo, sobre registro y depósito de convenios y acuerdos colectivos de trabajo. La Administración de la Seguridad Social facilitará la tasa de ocupación de las trabajadoras respecto de la totalidad de trabajadores por cuenta ajena en cada una de las CNAE correspondientes en la fecha de constitución de la comisión negociadora del convenio".

Posteriormente el precepto establece otra precisión: "En el CNAE al que esté adscrita la persona afectada por la aplicación de esta cláusula concurra una tasa de ocupación de empleadas inferior al 20 por ciento sobre el total de personas trabajadoras a la fecha de efectos de la decisión extintiva. Este CNAE será el que resulte aplicable para la determinación de los tipos de cotización para la cobertura de las contingencias de accidentes de trabajo y enfermedades profesionales".
} 
de política de derecho por la convivencia de un régimen diferente de jubilación forzosa con edades diferentes dentro del vigente sistema normativo. En el ámbito del régimen funcionarial, la jubilación forzosa por razón de la edad es una figura clásica, junto a la jubilación voluntaria y la jubilación por imposibilidad física ${ }^{12}$. Sin embargo, lo más llamativo es que el art. 67.3 del EBEP mantiene la jubilación de los funcionarios a los 65 años, con carácter general. Es verdad que, el art. 67.4 EBEP establece que la edad de la jubilación forzosa del personal funcionario incluido en el Régimen General de la Seguridad Social será, en todo caso, la que prevean las normas reguladoras de dicho régimen para el acceso a la pensión de jubilación en su modalidad contributiva sin coeficiente reductor por razón de la edad. Sin embargo, se mantiene una clara diferencia entre la jubilación forzosa de los funcionarios de los Regímenes especiales de Seguridad Social, y los de del RGSS, y de los primeros con la edad de jubilación forzosa prevista en la DA $10^{\mathrm{a}} \mathrm{ET}$.

Para entender la diferencia hay que partir de que desde la perspectiva de la Administración, la jubilación forzosa no ha perseguido jamás un objetivo directo de reparto de empleo, sino de mejor funcionamiento de la Administración, y ahorro de costes de personal. En ese sentido, resulta curioso que no se haya procedido a alargar la edad de jubilación de los funcionarios y se mantenga la institución de la jubilación forzosa. En este terreno, se advierte con nitidez las específicas características de una política sólo aparentemente contradictoria. Y es que ello se explica por un objetivo de recorte de gastos en la Administración, no interesada en el alargamiento de la vida activa de su personal, al ser profesionales con retribuciones por antigüedad elevadas.

A este respecto, conviene traer a colación que la edad de jubilación de los funcionarios públicos se rebajó con carácter general a los 65 años en 1984. Empero, dicha rebaja no fue interpretada por muchos funcionarios como un avance social, en particular en los niveles altos de funcionarios de la Administración, fundamentalmente por la merma de ingresos que se producía al cesar en su vida activa por las diferencias entre el salario en activo y los haberes pasivos. No es intrascendente poner de manifiesto que diversas SSTC han reconocido que no existe un derecho adquirido de los funcionarios a jubilarse a una edad de jubilación determinada (la del momento de su ingreso a la función pública), sino que el régimen funcionarial puede ser alterado por la potestad del legislador, pudiendo causar en algunos casos unos perjuicios compensables económicamente. El TS, no sin ciertas vacilaciones, acabaría por rechazar la posible responsabilidad patrimonial del Estado por la anticipación de la edad legal de jubilación respecto a la regulación anteriormente prevista en esencia, al no tratarse de un derecho patrimonializado del funcionario ni una medida expropiatoria de derechos ${ }^{52}$.

En la situación actual hay un claro contraste con la edad de jubilación forzosa de los funcionarios. El art. 67.3 EBEP habla de los 65 años y el art. 26 del Estatuto Marco del personal estatutario. Es verdad que se han anunciado cambios en el régimen de clases pasivas o para colectivos de funcionarios. Pero esto es complejo, reformar pensiones de funcionarios es abrir una caja de pandora. Un gobierno puede salir muy escaldado, salvo que las reformas sean favorables para los funcionarios. En el caso de los notarios y registradores que tenían la edad de jubilación forzosa a los

\footnotetext{
${ }^{12}$ El fundamento de la jubilación forzosa en el ámbito funcionarial estaría en una especie de presunción de ineptitud. Ha de tenerse en cuenta que la configuración inicial de la jubilación como causa de extinción se realiza históricamente en el marco de la invalidez. Al no existir en principio una protección social de la vejez, el funcionario debía continuar su prestación laboral para garantizarse la subsistencia, por tanto, no existía una causa de extinción para los funcionarios fundada en el hecho natural del envejecimiento del individuo. En este sentido, la edad actuaba como una de las causas de desgaste fisiológico que podían motivar la terminación de la prestación de servicios. Buena muestra de la primacía de esta concepción de la vejez en el marco de la Administración pública lo constituye las primera disposición, que con carácter general, reconoció el derecho de jubilación: la Real Orden de 23 de diciembre de 1776, por imposibilidad física referida a los individuos de resguardo de Madrid, o bien, el Real Decreto de 13 de octubre de 1828, que preveía la posibilidad de jubilar a los empleados, cuando por su avanzada edad o por alguna enfermedad habitual se hallasen absolutamente imposibilitados de continuar el servicio. Asimismo, la propia denominación de la pensión de jubilación como pensión de "retiro", denominación que aún se conserva en el ámbito militar, presupone el apartamiento de los funcionarios por una presunta ineptitud para continuar prestando la relación funcionarial.
} 
70 años, se posibilita su alargamiento voluntario hasta los $72^{13}$, pero ahí se juega en otro terreno, pues muchos lo habían reclamado porque no les interesaba jubilarse por el salto de lo que cobra un notario o registrador en activo y cuando se jubila, aunque cobre la máxima.

\section{La orientación de limitar las jubilaciones forzosas, pero ¿qué hay de las prejubilaciones?}

La habilitación legal para establecer cláusulas convencionales de jubilación forzosa en términos más estrictos despeja parte de los problemas relacionados con estas cláusulas, pero traslada la cuestión a otro terreno, pues muchas veces las jubilaciones forzosas se han establecido en los convenios colectivos para facilitar las reestructuraciones en las empresas, encubriendo una suerte de despido sin derecho a indemnización. Aunque el tribunal constitucional ya descartó, en un grupo de sentencias, que esta limitación de la libertad de trabajo de los trabajadores de más edad fuera inconstitucional ${ }^{14}$, la nueva orientación plantea algunas cuestiones en el terreno de las medidas de reestructuración para rejuvenecer la plantilla y, por qué no decirlo, amortizar puestos de trabajo. Obviamente el tema conecta con la selección de los trabajadores mayores en despidos colectivos y objetivos y las prejubilaciones.

La utilización del criterio de la edad como selección en despidos colectivos y objetivos ha planteado la duda sobre si, como en otros ordenamientos, como el norteamericando, ello puede resultar discriminatorio o violar los derechos fundamentales y libertades públicas del trabajador (art. 55.5 TRET 2015 en relación con Directiva 98/59 en materia de despido colectivo, en el que la edad, no debe influir en la decisión empresarial y Directiva 2000/78 y arts. 4.2 y 17 ET), y puede conducir a la calificación de nulidad del cese. Es verdad que hasta hace bien poco, apenas existían impugnaciones por discriminación en los despidos por causas empresariales que afectaban mayoritariamente a trabajadores de 52 o 55 años, en buena medida porque la adscripción a los despidos colectivos era casi siempre voluntaria y se combinaba con medidas de prejubilación. Sin embargo, el panorama ha empezado a cambiar, al hacerse difíciles y caras las prejubilaciones, y desparecer buena parte de las redes de protección más allá de los dos años de protección por desempleo. En relación con la edad como criterio de selección, la doctrina que ha examinado el tema ha señalado que la respuesta judicial es menos exigente que con otros criterios como la discapacidad o el género $^{15}$. La principal referencia es la STC 66/2015, de 13 de abril, que desestimó un recurso de amparo planteado en relación con la utilización del criterio de la edad superior a cincuenta y cinco años como factor determinante para la selección de los trabajadores afectados por un despido colectivo. El pronunciamiento consideró que la selección de trabajadores no era discriminatoria por la edad, dada la mayor protección social brindada a los mayores de cincuenta y cinco años. De manera, que "sólo puede considerarse legitima y proporcionada si se ve acompañada de medidas efectivas que atenúen los efectos negativos generados por la situación de desempleo, sin que en ningún caso pueda considerarse justificación suficiente del despido la mera proximidad de la edad de jubilación"16. En la misma línea,

${ }^{13}$ Acogiendo una enmienda del PDCAT, se ha regulado en la DF 6a Ley 21/21 modifica artículo primero de la Ley 29/1983, de 12 de diciembre, sobre jubilación de Notarios, Agentes de Cambio y Bolsa y Corredores colegiados de Comercio

${ }^{14}$ Sentencias del Tribunal Constitucional 58/1985, de 30 de abril, 95/1985, de 29 de julio, y 111/1985 a 136/1985, de 11 de octubre.

${ }^{15}$ Sobre esta cuestión, Martínez Barroso, M.R. (2019). Despidos colectivos de trabajadores de edad avanzada y protección social: entre la discriminación y la eficiencia. Revista de trabajo y Seguridad Social. CEF, 430, 15-51.

${ }^{16}$ El TC descartó esta discriminación sobre la base de varios argumentos: primero, obligación de la empresa de suscribir un convenio especial de seguridad social para los mayores de 55 años. Segundo, otras medidas de compensación social para evitar o minimizar los efectos del despido. La sentencia tuvo crítica en un sector de la doctrina por basarse en argumentos eficientistas, que solo tienen en cuenta los intereses de la empresa y los trabajadores como sujetos directamente interesados, no teniendo en cuenta los de la 
otros pronunciamientos judiciales en la jurisdicción social han descartado en su mayoría el carácter discriminatorio de la selección de los trabajadores mayores, y a ello ha contribuido el carácter casi siempre voluntario de las prejubilaciones ${ }^{17}$.

Al hilo de lo anterior, conviene analizar el tema de las prejubilaciones, que han venido siendo dificultadas en sucesivas reformas de Seguridad Social. El cambio normativo que más ha erosionado la eficacia de las prejubilaciones es la aportación al Tesoro público por despidos colectivos de trabajadores de 50 o más años, en empresas en beneficios ${ }^{18}$, aunque han existido otros ${ }^{19}$. Pero estos cambios no han impedido las prejubilaciones en empresas solventes. Ello contrasta con los costes sociales e individuales de un despido colectivo y las prejubilaciones. Y es que las prejubilaciones tienen un impacto que va más allá de las empresas, personas y sindicatos afectados, y que conviene no perder de vista, incluso cuando los sujetos intervinientes han cerrado a plena satisfacción un proceso de despido colectivo. Los costes sociales e individuales de un despido que pueden agravarse o amortiguarse en función de los mismos o la protección de trabajadores especialmente protegidos, genera más gastos a las arcas públicas el despido de trabajadores de edad o con discapacidad. Sin embargo, en nuestro ordenamiento, a diferencia de otros que incluyen a unos $\mathrm{u}$ otros como trabajadores que deben estar sometidos a una especial tutela, no se ha considerado discriminatorio que el despido colectivo afecte mayormente a trabajadores de edad avanzada ${ }^{20}$, sobre la base de los dos argumentos antes comentados. Es decir, de una visión centrada en el carácter voluntario de la adscripción a las prejubilaciones y que generalmente el prepensionista tenía garantizado sus ingresos hasta la jubilación. En nuestro sistema ha predominado una visión "individualista" de las consecuencias de las prejubilaciones, que ha posibilitado prejubilaciones masivas en sectores como el financiero ${ }^{21}$. Sin embargo, en algunos países como Alemania, los criterios de selección de las personas afectadas por un despido colectivo son una cuestión enjuiciada con otros parámetros. En esencia, se entiende que las decisiones empresariales del despido forman parte del funcionamiento económico de la empresa y no son cuestionables por los órganos judiciales. También que los aspectos sociales del despido, como planes sociales, indemniza-

Seguridad Social y olvidando la apuesta gubernativa por el envejecimiento activo. Solà Monells, X. (2016), La afectación prioritaria de los trabajadores de mayor edad en el despido colectivo, pp. 12-24.

${ }^{17}$ Por todas, STS de 14 de diciembre de 2017, rec. 17/2017, que ha considerado razonable conectar los excedentes de plantilla que han de amortizarse con los trabajadores próximos a la edad de jubilación.

${ }^{18}$ Regulado en la DA 16a de la Ley 27/2011.

${ }^{19}$ Así, en primer lugar, la protección por desempleo que es la primera a la que suele acceder el prejubilado y que como es sabido, se extendería a dos ańos, si el trabajador acredita seis ańos de cotización, se ha visto reducida en su cuantía, a partir de los seis primeros meses de percepción. Además, la utilización del subsidio por desempleo de mayores, conocido como prejubilación, se ha visto afectado por diferentes modificaciones legales que han reducido su nivel de protección. Entre ellas, el endurecimiento de la forma de determinar la renta por encima de la cual se excluye el derecho al subsidio; el mantenimiento del subsidio hasta la primera edad posible de jubilación y no hasta la edad ordinaria, y la reducción de la base de cotización. El cuarto punto es que el acceso a la jubilación anticipada se ha visto sometido a requerimientos cada vez más exigentes.

${ }^{20}$ Por todas, STS (C-A) de 15 de junio de 2005, rec. núm. 7284/2000;_6

${ }^{21}$ Por ejemplo, el despido colectivo efectuado en CAIXABANK que fue acordado en período de consultas. Inicialmente la representación empresarial pretendía realizar más de 6.000 despidos, proponiendo varios criterios. Estas propuestas merecieron reacciones políticas y sindicales, que, entre otros aspectos, incidieron en que una de las entidades bancarias fusionadas había sido salvada con dinero público y que era inadmisible que transcurridos unos años se procediera al mayor despido colectivo en la historia de España. Tras varias huelgas, la representación sindical consiguió reducir el número de despidos y un plan de prejubilaciones al que los trabajadores de las entidades fusionadas podían adscribirse voluntariamente. El período de consultas del procedimiento de despido colectivo y modificación de condiciones de trabajo promovido tras la fusión concluyó con "Acuerdo de finalización del período de consultas" que se formalizó el 7 de julio de 2021. Las consecuencias de este acuerdo fueron las siguientes. En primer lugar, el volumen de personas trabajadoras que solicitaron estas prejubilaciones superó ampliamente las previsiones dadas las excelentes condiciones "conseguidas" (apropiándome aquí del adjetivo utilizado por algún portavoz sindical). En segundo lugar, los sindicatos participantes manifestaron su satisfacción por el acuerdo conseguido. En tercer lugar, la empresa sufrió una subida en bolsa tras el proceso de reestructuración con acuerdo. Finalmente, el gobierno de coalición manifestó su respeto por el acuerdo en período de consultas. En conclusión, el balance del que, algunos medios de prensa calificaron como el mayor despido colectivo efectuado en España, sería a priori positivo para todos los intervinientes. Sin embargo, no está claro que esta sea la única valoración y que el acuerdo no sea bueno para todos, que haya una víctima silenciada: el conjunto de la sociedad. 
ciones, etc., deben negociarse con la representación de los trabajadores. Entonces, ¿dónde se centra el examen judicial de los despidos por razones empresariales? En síntesis, el control judicial debe posibilitar un despido de los mejor preparados para reinsertarse en el mercado de trabajo precisamente por los costes sociales que genera un despido colectivo (en materia de prestaciones por desempleo, ayudas a la recualificación profesional y otras políticas públicas) ${ }^{22}$.

Es un criterio diferente al seguido en nuestro ordenamiento que ha permitido durante bastante tiempo la afectación -casi libre- de los trabajadores de edad avanzada, sin que las limitaciones de contribución de las empresas solventes haya resuelto este controvertido tema, posibilitando la amortización de puestos de trabajo o que la empresa sustituya la mano de obra por trabajadores baratos, por ejemplo, mediante contratas.

\section{Conclusiones}

En conclusión, la nueva redacción de la DA 10a ET introuce una limitación de las cláusulas de jubilación forzosas en convenios colectivos: en términos de edad y de política de empleo, pero se ha establecido un régimen de transitoriedad, o, mejor dicho, de vigencia para las cláusulas de los convenios vigentes con anterioridad al cambio normativo. Además, por primera vez se ha previsto un sesgo de género como posibilidad en las jubilaciones forzosas convencionales en sectores de baja ocupación femenina.

El régimen de la jubilación forzosa laboral establecida en convenio colectivo y la edad fijada contrasta con el régimen funcionarial de la institución y la edad para este colectivo. Asimismo, otro plano de contraste se relaciona con la posibilidad de prejubilaciones, que pese a su encarecimiento, continúan siendo una vía preferente de amortización de puestos de trabajo, en empresas solventes.

${ }^{22}$ Sobre los distintos modelos de regulación de los criterios de selección en el Derecho comparado europeo puede verse TORMOS PÉREZ, J.A .: Los criterios de selección de los trabajadores afectados por el despido colectivo, Tesis Doctoral, 2019, pp. 42-54. 